\title{
Unprecedented hetero-geometric discrete copper(II) complexes: Crystal structure and bio-mimicking of Catecholase activity
}

\author{
ABHRANIL DE ${ }^{\mathrm{a}}$, DHANANJAY DEY ${ }^{\mathrm{a}}$, HARE RAM YADAV ${ }^{\mathrm{b}}$, MILAN MAJI $^{\mathrm{c}}$, \\ VINAYAK RANE $^{\mathrm{d}}, \mathrm{R}^{\mathrm{M}}$ KADAM $^{\mathrm{d}}$, ANGSHUMAN ROY CHOUDHURY ${ }^{\mathrm{b}}$ and \\ BHASKAR BISWAS ${ }^{\mathrm{a}, *}$ \\ ${ }^{a}$ Department of Chemistry, Raghunathpur College, Purulia, West Bengal, 723133 India \\ ${ }^{b}$ Department of Chemical Sciences, Indian Institute of Science Education and Research Mohali, Sector 81, \\ S A S Nagar, Manauli P. O. Mohali, Punjab, 140 306, India \\ ${ }^{\mathrm{c}}$ Department of Chemistry, National Institute of Technology, Mahatma Gandhi Avenue, Durgapur, \\ West Bengal, 713 209, India \\ ${ }^{\mathrm{d}}$ Radiochemistry Division, Bhabha Atomic Research Centre, Trombay, Mumbai, Maharashtra 400085 , India \\ e-mail: icbbiswas@gmail.com; mr.bbiswas@rediffmail.com
}

MS received 30 March 2016; revised 22 June 2016; accepted 5 September 2016

\begin{abstract}
An unprecedented solid of coper(II) complexes, $\left[\mathrm{Cu}(\mathrm{dpa})_{2} \mathrm{NCS}\right]_{2}\left[\mathrm{Cu}(\mathrm{dpa})_{2}(\mathrm{NCS})_{2}\right]\left(\mathrm{ClO}_{4}\right)_{2}(\mathbf{1})$ $\left[\mathrm{dpa}=2,2^{\prime}\right.$-dipyridylamine; $\mathrm{SCN}=$ thiocyanate], has been synthesized and crystallographically characterized with the aim to study the catecholase activity. The $\mathrm{Cu}$ (II) complex mimics the full catalytic cycle of the active site of catechol oxidase enzyme in acetonitrile medium with a turnover number of $4.788 \times 10^{3} \mathrm{~h}^{-1}$ along with the production of semiquinone radical and hydrogen peroxide. In situ generation of $\mathrm{Cu}(\mathrm{I})$ species in the catalytic pathway of catechol oxidation was established by electrochemical study and further confirmed by electron paramagnetic resonance (EPR) spectroscopy.
\end{abstract}

Keywords. Copper; X-ray structure; radical activity; catechol oxidase activity.

\section{Introduction}

The efficiency and selectivity of copper proteins to process dioxygen has received considerable attraction to synthetic coordination chemists for the investigation of spectroscopic, structural and catalytic properties. ${ }^{1}$ Bio-catalysis mediated by copper complexes at ambient conditions is at the fundamental stage in Bioinorganic chemistry. Transition metal ions in oxidase or oxygenase serve to activate the kinetically inert $\mathrm{O}_{2}$, and is used to mediate multi-electron redox reactions. ${ }^{2,3}$ Thus, it is of paramount interest to understand the basic functional principles that govern such bi- or polymetallic reactivity of natural enzymes. Dicopper sites play a pivotal role in biological oxidation and, consequently, the understanding of structural and functional aspects of copper metalloenzymes is a subject of intensive research. ${ }^{4-7}$ A prominent member of these copper proteins is catechol oxidase, which is a type 3 copper protein $^{8}$ and catalyzes exclusively the oxidation of catechols to the corresponding $o$-quinones.

On the other hand, the catecholase activity by various dicopper compounds with different structural

\footnotetext{
*For correspondence
}

connectivities has been widely investigated. ${ }^{9}$ Mononuclear copper(II) complexes, ${ }^{10}$ a few copper(II) clusters and polymers have been found to be active catalysts. ${ }^{11,12}$ Explorations of catecholase activity by new types of compounds are very much demanding. Murphy et al., ${ }^{13}$ Arriortua et al. ${ }^{14}$ and Sletten et al.,${ }^{15}$ have reported the same class of copper(II) complexes containing dipyridylamine and thiocyanate ions but none of these groups till date have been able to explore the catecholase activity using such $\mathrm{Cu}$ (II) complexes as active catalytic system. Herein, we report the addition of a new catalytic system in the form of discrete hetero-geometric copper(II) complex, $\left[\mathrm{Cu}(\mathrm{dpa})_{2} \mathrm{NCS}_{2}\left[\mathrm{Cu}(\mathrm{dpa})_{2}(\mathrm{NCS})_{2}\right]\right.$ $\left(\mathrm{ClO}_{4}\right)_{2}(\mathbf{1})\left[\mathrm{dpa}=2,2^{\prime}\right.$-dipyridylamine; $\mathrm{NCS}=$ thiocyanate], which also potentially mimics the full catalytic cycle of functional models of the active site of catechol oxidase enzyme with significant turnover number along with the production of semiquinone and hydrogen peroxide. The generation of $\mathrm{Cu}(\mathrm{I})$ species in the catalytic pathway established by electrochemical analysis was further confirmed by electron paramagnetic resonance (EPR) spectroscopy. EPR titration suggests that the generation of radical of catechol in presence of copper complex is playing a key role towards the catecholase-like activity. 


\section{Experimental}

\subsection{Materials}

High purity 2,2'-dipyridylamine (Aldrich, UK)), copper(II) perchlorate hexahydrate (Fluka, Germany), ammonium thiocyanate chloride (E. Merck, India), 3,5di-tert-butylcatechol (Sigma Aldrich Corporation, St. Louis, MO, USA), and all other materials were obtained from commercial sources and used as received. All other chemicals and solvents were of analytical grade and were used as received without further purification.

Caution! Perchlorate salts of metal ions are potentially explosive, especially in the presence of organic ligands. Only a small amount of material should be prepared and it should be handled with care.

\subsection{General synthesis of the copper(II) complex (1)}

The discrete hetero-geometric copper complex was synthesized by dropwise addition of aqueous solution of dipyridylamine $(0.342 \mathrm{~g}, 2 \mathrm{mmol})$ into a solution of $\left.\mathrm{Cu}\left(\mathrm{ClO}_{4}\right)_{2} \cdot 6 \mathrm{H}_{2} \mathrm{O}(0.365 \mathrm{~g}, 1 \mathrm{mmol})\right]$ in the same solvent $(20 \mathrm{~mL})$ keeping the solution on magnetic stirrer with slow stirring $(450 \mathrm{rpm})$. Then solid ammonium thiocyanate $(0.076 \mathrm{~g}, 1 \mathrm{mmol})$ was added as solid into the blue solution and stirring continued to 30 minutes more. The blue solution turned into green and the supernatant liquid was kept in air for slow evaporation. After 7-10 days, fine microcrystalline compound 1 was separated out, which was washed in hexane and dried in vacuo over silica gel indicator. The spectroscopic measurements and elemental analyses confirmed the structural formation of the complex. Yield $=0.2870 \mathrm{~g}$, (65.1\% based on metal salt and thiocyanate). Anal. calc. (\%) $\mathrm{C}_{64} \mathrm{H}_{54} \mathrm{~N}_{22} \mathrm{Cl}_{2} \mathrm{O}_{8} \mathrm{~S}_{4} \mathrm{Cu}_{3}$ (1): C, 46.61; H, 3.30; N, 18.69; Found (\%): C, 46.66; H, 3.24; N, 18.73. Selected IR bands (KBr pellet, $\mathrm{cm}^{-1}$ ): 3353 (s), 2142 (s), 1426 (m), 1616 (s), 1096 (s). UV-Vis $\left(\lambda, \mathrm{nm} ; 10^{-4} \mathrm{M}, 1 \mathrm{~cm}\right.$ cell, abs): 250-269 (4.068), 290-320 (3.7201), 397 (0.1688), 682 (0.0216) (broad); ESI-MS (MeCN): $\mathrm{m} / \mathrm{z}, 235.95$ (calcd. 235.75) $[\mathrm{Cu}(\mathrm{dpa})] \mathrm{H}^{+} ; \mathrm{m} / \mathrm{z}, 525.91$ (calcd. 525.05) $\left[\mathrm{Cu}(\mathrm{dpa})_{2}(\mathrm{NCS})_{2}\right] \mathrm{H}^{+}$.

\subsection{Physical measurements}

Infrared spectrum $(\mathrm{KBr})$ was recorded with a FTIR8400S SHIMADZU spectrophotometer in the range $400-3600 \mathrm{~cm}^{-1} .{ }^{1} \mathrm{H}$ NMR spectrum in DMSO- $d_{6}$ was obtained on a Bruker Avance $300 \mathrm{MHz}$ spectrometer at $25^{\circ} \mathrm{C}$ and was recorded at $299.948 \mathrm{MHz}$. Absorption spectra were recorded with a Jasco model V-730
UV-Vis spectrophotometer. Elemental analyses were performed on a Perkin Elmer 2400 CHN microanalyser. Electrospray ionization (ESI) mass spectrum was recorded on a Q-TOF Micro ${ }^{\mathrm{TM}}$ Mass Spectrometer. Cyclic voltammograms were recorded in $\mathrm{CH}_{3} \mathrm{CN}$ solutions containing $0.1 \mathrm{M} \mathrm{TBAP}$ at $25^{\circ} \mathrm{C}$ using a three-electrode configuration ( $\mathrm{Pt}$ working electrode, Pt counter electrode, $\mathrm{Ag} / \mathrm{AgCl}$ reference) and a $\mathrm{PC}$ controlled PAR model 273A electrochemistry system. All the experimental solutions were degassed for 30 minutes with high-purity argon gas. The Electron Paramagnetic Resonance (EPR) spectrum was recorded on a Bruker EMX-X band spectrometer (Model: EMX).

\section{$2.4 X$-ray diffraction}

Single crystal X-ray diffraction data of the copper complex were collected using a Rigaku XtaL ABmini diffractometer equipped with Mercury CCD detector. The data were collected with graphite monochromated Mo-K $\alpha$ radiation $(\lambda=0.71073 \AA$ ) at $293(2) \mathrm{K}$ using $\omega$ scans. The data were reduced using Crystal Clear suite 2.0. ${ }^{16}$ and the space group determination was done using $\mathrm{Olex}^{2}$. The structure was resolved by direct method and refined by full-matrix least-squares procedures using the SHELXL-2014/ $/ 7^{17}$ software package using OLEX2 suite. ${ }^{18}$ The crystallorgraphic bond distance and bond angle were calculated using PARST ${ }^{19}$ and given in Tables 1 and 2, respectively.

Table 1. Crystallographic parameters for $\mathbf{1}$.

\begin{tabular}{lc}
\hline Crystal parameters & $\mathbf{1}$ \\
\hline Empirical formula & $\mathrm{C}_{64} \mathrm{H}_{54} \mathrm{~N}_{22} \mathrm{Cl}_{2} \mathrm{O}_{8} \mathrm{~S}_{4} \mathrm{Cu}_{3}$ \\
& 1649.08 \\
Formula weight & $293(2) \mathrm{K}$ \\
Temperature & $0.71073 \AA$ \\
Wavelength & Monoclinic \\
Crystal system & $P 2_{1} / \mathrm{c}$ \\
Space group & $\mathrm{a}=12.7156(8) \AA \alpha=90^{\circ}$ \\
Unit cell dimensions & $\mathrm{b}=14.4230(9) \AA \AA=93.802^{\circ}(3)$ \\
& $\mathrm{c}=19.3355(12) \AA \gamma=90^{\circ}$ \\
Volume & $3538.3(4) \AA^{3}$ \\
$Z$ & 8 \\
Density (calculated) & $1.548 \mathrm{~g} \mathrm{~cm}^{-3}$ \\
Absorption coefficient & $1.158 \mathrm{~mm}^{-1}$ \\
F(000) & 1682 \\
Theta range for data collection & 3.0 to $27.5^{\circ}$ \\
Reflections collected & 35795 \\
Independent reflections & 7978 \\
R(int) & 0.056 \\
R indices (all data) & $\mathrm{R} 1=0.0761, \mathrm{wR}^{\circ}=0.2239$ \\
Largest diff. peak and hole & 1.31 and $-0.92 \mathrm{e} . \AA^{-3}$ \\
\hline
\end{tabular}


Table 2. Bond angle and bond distances of $\mathbf{1}$.

\begin{tabular}{lccr}
\hline Bond distances & & & \\
Cu2-N8 & $2.020(3)$ & Cu1-N7 & $1.995(4)$ \\
Cu2-N10 & $2.004(3)$ & Cu1-N3 & $2.138(4)$ \\
Cu2-N11_b & $2.494(6)$ & Cu1-N4 & $1.992(4)$ \\
Cu2-N11_c & $2.494(6)$ & Cu1-N1 & $2.020(4)$ \\
Cu2-N8_d & $2.020(3)$ & Cu1-N6 & $2.012(4)$ \\
Cu2-N10_d & $2.004(3)$ & & \\
Bond angles & & & \\
N8-Cu2-N10 & $85.46(14)$ & N10_d-Cu2-N11_b & $85.56(17)$ \\
N8-Cu2-N11_b & $89.40(17)$ & N8_d-Cu2-N11_c & $89.40(17)$ \\
N8-Cu2-N11_c & $90.60(17)$ & N10_d-Cu2-N11_c & $94.45(17)$ \\
N8-Cu2-N8_d & 180.00 & N8_d-Cu2-N10_d & $85.46(14)$ \\
N8-Cu2-N10_d & $94.54(14)$ & N3-Cu1-N6 & $100.73(16)$ \\
N10-Cu2-N11_b & $94.45(17)$ & N3-Cu1-N7 & $102.76(17)$ \\
N10-Cu2-N11_c & $85.56(17)$ & N4-Cu1-N6 & $88.26(16)$ \\
N8_d-Cu2-N10 & $94.54(14)$ & N4-Cu1-N7 & $87.73(17)$ \\
N10-Cu2-N10_d & 180.00 & N6-Cu1-N7 & $156.45(18)$ \\
N11_b-Cu2-N11_c & 180.00 & N1-Cu1-N6 & $93.11(14)$ \\
N8_d-Cu2-N11_b & $90.60(17)$ & N1-Cu1-N7 & $86.26(15)$ \\
N3-Cu1-N4 & $103.79(16)$ & N1-Cu1-N3 & $87.71(15)$ \\
N1-Cu1-N4 & $167.97(15)$ & & \\
\hline
\end{tabular}

\subsection{Catalytic oxidation of 3,5-DTBC}

In order to study the catecholase activity of the complex, a $10^{-4} \mathrm{M}$ solution of $\mathbf{1}$ in acetonitrile was treated with 100 equiv. of 3,5-di-tert-butylcatechol (3,5DTBC) under aerobic conditions at room temperature. Absorbance vs. wavelength (wavelength scans) of these solutions were recorded at a regular time interval of $5 \mathrm{~min}$ in the wavelength range $300-900 \mathrm{~nm}$.

The kinetics of oxidation of 3,5-DTBC were determined by the method of initial rates and monitored the growth of the quinone band at $393 \mathrm{~nm}$ as a function of time. ${ }^{20-23}$ Kinetic experiment was performed with $\mathbf{1}$ (at a constant concentration of $1 \times 10^{-4} \mathrm{M}$ ) and 3,5DTBC (varying the concentration from $1 \times 10^{-3} \mathrm{M}$ to $1 \times 10^{-2} \mathrm{M}$ ) in acetonitrile using UV-Vis spectrophotometer. $2 \mathrm{~mL}$ of 3,5-DTBC solution at appropriate concentration, obtained by accurate dilution from the stock solution, was taken in the UV-Vis quartz cell $(1 \mathrm{~cm})$ and kept for a while inside the cell holder which was attached with a thermostat to keep the temperature at $25^{\circ} \mathrm{C}$. Then, $0.04 \mathrm{~mL}$ of stock solution of the complex was added to it to achieve the ultimate concentration of the complex as $1 \times 10^{-4} \mathrm{M}$. The formation of 3,5-DTBQ was monitored with time at a wavelength of $393 \mathrm{~nm}$. Each experiment was performed in triplicate.

\subsection{Detection of hydrogen peroxide in the catalytic oxidation of 3,5-DTBC}

To detect the formation of hydrogen peroxide during the catalytic reaction, we followed a previously reported method. ${ }^{24}$ Reaction mixtures were prepared as in the kinetic experiments. During the course of the oxidation reaction, the solution was acidified with $\mathrm{H}_{2} \mathrm{SO}_{4}$ to $\mathrm{pH}$ 2 to stop further oxidation after a certain time and an equal volume of water was added. The formed quinone was extracted three times with dichloromethane. $1 \mathrm{~mL}$ of $10 \%$ solution of KI and three drops of $3 \%$ solution of ammonium molybdate were added to the aqueous layer. The formation of $\mathrm{I}^{3-}$ could be monitored spectrophotometrically because of the development of the characteristic $\mathrm{I}^{3-}$ band $\left(\lambda_{\max }=353 \mathrm{~nm}, \varepsilon\right.$ (extinction coefficient) $\left.=4741 \mathrm{M}^{-1} \mathrm{~cm}^{-1}\right)$.

\section{Results and Discussion}

\subsection{Synthesis and formulation}

The hetero-geometric discrete copper(II) complex (1) was synthesized by addition of 2,2'-dipyridylamine to a solution of $\mathrm{Cu}\left(\mathrm{ClO}_{4}\right)_{2} \cdot 6 \mathrm{H}_{2} \mathrm{O}$ followed by the addition of ammonium thiocyanate $\left(\mathrm{NH}_{4} \mathrm{SCN}\right)$ in aqueous solution at room temperature (Scheme 1). The structural formulation was determined by using routine spectroscopic techniques including single crystal X-ray diffraction analysis.

\subsection{Description of crystal structure}

The X-ray crystal structure analysis of $\mathbf{1}$ reveals that hetero-geometric copper((II) complex (1) crystallizes in monoclinic crystal system with $P 2_{1} / c$ space group. 

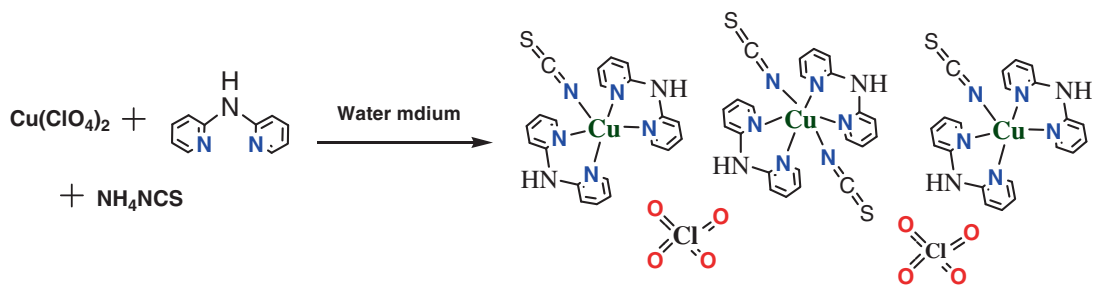

Scheme 1. Synthesis of the copper(II) complex.

An ORTEP of the copper complex is shown in the Figure 1. Two isostructural independent monocationic, $\left[\mathrm{Cu}(\mathrm{dpa})_{2} \mathrm{NCS}\right]^{+}$units and one trans- $\left[\mathrm{Cu}(\mathrm{dpa})_{2}(\mathrm{NCS})_{2}\right]$ unit crystallized through $\mathrm{S} \cdots \mathrm{H}$ bonds and the residual two units of cationic charge, is counterbalanced by two perchlorate ions in the unit cell. Between the two hetero-geometric copper centers, $\mathrm{Cu} 2$ center is in octahedral geometry and the primary zone of $\mathrm{Cu} 2$ is coordinated by nitrogen atoms of the dipyridyl ligands in equatorial plane $[\mathrm{Cu} 2-\mathrm{N} 8=2.020(3) \AA, \mathrm{Cu} 2-\mathrm{N} 10=$ 2.004(3) $\AA$ ] with two axially occupied thiocyanate ligands, $\mathrm{Cu} 2-\mathrm{N} 1=2.494(6) \AA$. In the complex unit, the geometry of cationic $\mathrm{Cu} 1$ unit may be best described as distorted square pyramidal (Figure 1) as evident from the value of the trigonal index, $\tau=0.063$; $[\tau=$ $|\beta-\alpha| / 60]$, where $\alpha=90^{\circ}$ and $\beta=93.802^{\circ} ; \tau$ is 1 for a perfect trigonal bipyramidal geometry and is zero for a perfect square pyramidal geometry. ${ }^{24} \mathrm{In}$ the $\mathrm{Cu} 1 \mathrm{com}$ plex unit, one of the two bidentate dipyridylamine ligands coordinates to $\mathrm{Cu}$ (II) center at apical $[\mathrm{Cu} 1-\mathrm{N} 3=$ $2.138(4) \AA$, and equatorial $[\mathrm{Cu} 1-\mathrm{N} 1=2.020(4) \AA]$ sites and the other dipyridylamine chelates to $\mathrm{Cu}$ (II) ions at equatorial positions [Cu1-N4 = 1.992(4) $\AA$, Cu1-N6 = 2.012(4) $\mathrm{A}$. The last equatorial site at $\mathrm{Cu} 1$ ions was coordinated by $\mathrm{N}$-atom of the isothiocyanate groups [Cu1-N7 = 1.995(4) $\AA$.

Molecular packing diagram of $\mathbf{1}$ indicates that square pyramidal copper $(\mathrm{Cu} 1)$ units coexist with octahedral copper $(\mathrm{Cu} 2)$ units through weak forces in solid state (Figure S1). Close observation of 1 suggests that $\mathrm{Cu} 2$ center acts as a center of inversion in the unit cell. $\mathrm{Cu} 1$ unit is attached with $\mathrm{Cu} 2$ unit via moderately strong $\mathrm{H}$-bonding between sulphur atoms of terminal thiocyanate ions and hydrogen atoms $[\mathrm{H}(2) \cdots \mathrm{S} 2$, $2.73 \AA$ A $H(4)$. . S2, $2.85 \AA$ A; Figure S2 (see Supplementary Information)].

\subsection{Electronic and EPR spectral characterization}

The integrity of the copper complex in solution was checked through UV-Vis and EPR spectral analysis. The UV-Vis spectrum for $\mathbf{1}$ in acetonitrile at room temperature shows a series of high intensity transitions in the range of 250 to 269 and 290 to $320 \mathrm{~nm}$ (Figure S3 in Supplementary Information) which are attributed from the intraligand transitions. A very broad low energy transition centered at $682 \mathrm{~nm}$ (Figure S3 in Supplementary Information) is assigned to the ligand field transition for the copper complex. The X-band EPR spectra of the copper complex (Figure S4 in Supplementary Information) at room temperature (RT) and low temperature (LT) were recorded in MeCN solution and examined to distinguish the hetero-geometry of copper centers in 1. Complex 1 consists of a three copper centers, with two being in square pyramidal and one in octahedral environment. However, the room temperature spectrum
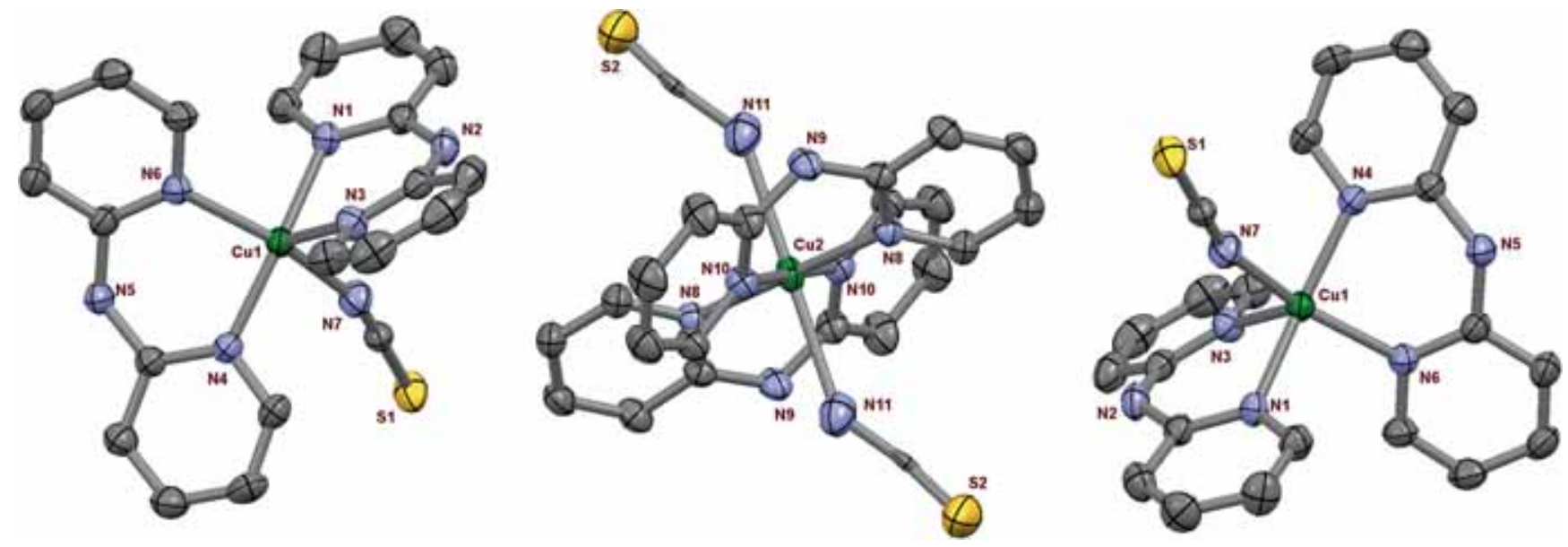

Figure 1. ORTEP of $\mathbf{1}^{2+}$ with $30 \%$ ellipsoid probability. 
showed the presence of a single species which was confirmed by simulating the spectrum (Figure S4 in Supplementary Information). This behavior could be understood since the three copper nuclei might behave as exchange couples so as to form a single species with a new spin state $S=1 / 2$. Low temperature experiments were also performed but were not helpful in differentiating the coordination environments of the metal centers. LT spectral analysis reveals the presence of four lines in the spectrum.

\subsection{Catechol oxidation activity}

The catalytic activities of $\mathbf{1}$ towards a standard substrate 3,5-di-tert-butylcatechol (3,5-DTBC) in acetonitrile medium under aerobic condition have been studied. Spectrophotometric scans revealed a gradual decrease in intensity of the band at $284 \mathrm{~nm}$ due to the gradual decline of catechol ${ }^{25,26}$ and an appearance of a new band with increasing intensity at $\sim 393 \mathrm{~nm}$ (Figure 2). The corresponding quinone (3,5-DTBQ) was purified by column chromatography and isolated in high yield (83.8\% for 1) by slow evaporation of the eluent. The

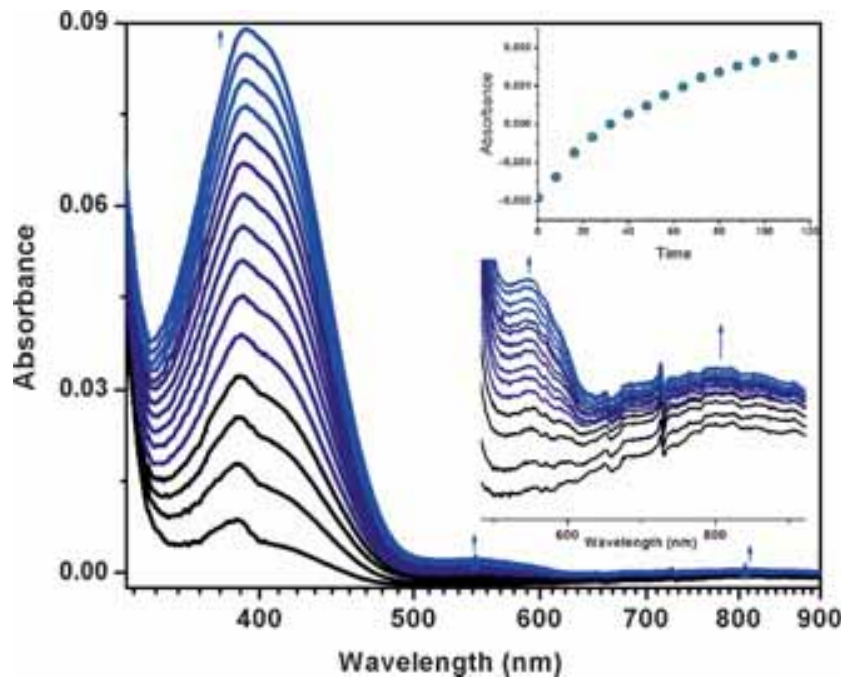

Figure 2. Increase of quinone band at $393 \mathrm{~nm}$ after addition of 100 equivalents of 3,5 -DTBC to a solution containing $1\left(10^{-4} \mathrm{M}\right)$ in acetonitrile at $25^{\circ} \mathrm{C}$ path length, $1 \mathrm{~cm}$. The spectra were recorded at an interval of $5 \mathrm{~min}$. Inset (bottom): Expanded plot. Inset (Top): Absorbance at $807 \mathrm{~nm}$ vs time plot to reveal the nature of oxidation reaction. product was identified by ${ }^{1} \mathrm{H}$ NMR spectroscopy. ${ }^{1} \mathrm{H}$ $\operatorname{NMR}\left(\mathrm{CDCl}_{3}, 400 \mathrm{MHz}\right) \delta_{\mathrm{H}}: 1.19(\mathrm{~s}, 9 \mathrm{H}), 1.22(\mathrm{~s}, 9 \mathrm{H})$, $6.14(\mathrm{~d}, J=2.4 \mathrm{~Hz}, 1 \mathrm{H}), 6.96(\mathrm{~d}, J=2.4 \mathrm{~Hz}, 1 \mathrm{H})$. The kinetics of oxidation of 3,5-DTBC by 1 were determined by the method of initial rates which involved monitoring the growth of the quinone band at $393 \mathrm{~nm}$ as a function of time. ${ }^{22-24}$ The rate constant versus concentration of the substrate data were then analyzed on the basis of the Michaelis-Menten approach of enzyme kinetics to get the Lineweaver-Burk plot (double reciprocal), as well as the values of the parameters $\mathrm{V}_{\max }, \mathrm{K}_{\mathrm{M}}$, and $\mathrm{k}_{\text {cat }}$. The observed rate constant versus substrate concentration plot for $\mathbf{1}$ in $\mathrm{MeCN}$ is shown in Figure S5 (see Supplementary Information). The kinetic parameters for $\mathbf{1}$ are listed in Table 3.

\subsection{Mechanistic aspects of catecholase activity}

Irreversible reduction and oxidation peaks for $\mathbf{1}$ were observed at -780 and $+35 \mathrm{mV}$ (Figure 3 ) at the scan rate of $20 \mathrm{mV} \mathrm{s}^{-1}$ suggesting that the reduction is quite difficult due to increase in the electron density significantly on central $\mathrm{Cu}$ (II) ion. To gain mechanistic insight of catechol oxidation by the $\mathrm{Cu}$ (II) complex, we have performed electrochemical analysis of the oxidation of 3,5-DTBC in presence and absence of the copper complex under aerobic atmosphere. A mixture containing one part of the complex and 100 parts of 3,5-DTBC were analysed by cyclic voltammetry without the purging of argon gas. ${ }^{24}$ The cyclic voltammogram of 3,5DTBC in presence of 1 (Figure 3) shows a reduction and an oxidation peak at -475 , and $+545 \mathrm{mV}$ with significant increase in the reduction peak current (Figure 3). An oxidation hump at approx. $+270 \mathrm{mV}$ for $\mathbf{1}$ in presence of 3,5-DTBC appeared due to the oxidation of $\mathrm{Cu}(\mathrm{I})$ which is generated in the catalytic pathway. The absence of the reduction peak of $\mathrm{Cu}(\mathrm{II})$ in the cyclic voltammogram of 3,5-DTBC in the presence of copper complex is indicative of the reduction of $\mathrm{Cu}$ (II) to $\mathrm{Cu}(\mathrm{I})$ during the course of electro-catalytic effect of the complex in which the 3,5-DTBC is oxidized to quinone.

The result of electrochemical analysis was further confirmed by EPR analysis. The room temperature $\mathrm{X}$-band frequency EPR spectrum of the complex (Figure 4) consists of quartet hyperfine structure

Table 3. Kinetic parameters for the catechol oxidation by $\mathbf{1}$.

\begin{tabular}{|c|c|c|c|c|c|c|}
\hline Solvent & $\mathrm{V}_{\max }\left(\mathrm{M} \mathrm{s}^{-1}\right)$ & Std. error & $\mathrm{K}_{\mathrm{M}}(\mathrm{M})$ & Std. error & $\mathrm{k}_{\text {cat }}\left(\mathrm{h}^{-1}\right)$ & References \\
\hline $\mathrm{MeCN}$ & $1.33 \times 10^{-4}$ & $2.82 \times 10^{-5}$ & $7.34 \times 10^{-3}$ & $4.8 \times 10^{-3}$ & $4.788 \times 10^{3}$ & This paper \\
\hline TRIS buffer & $9.63 \times 10^{-4}$ & - & $1.33 \times 10^{-4}$ & - & 63 & 27 \\
\hline TRIS buffer & $8.9 \times 10^{-5}$ & - & $1.33 \times 10^{-4}$ & - & $5.06 \times 10^{2}$ & 27 \\
\hline
\end{tabular}



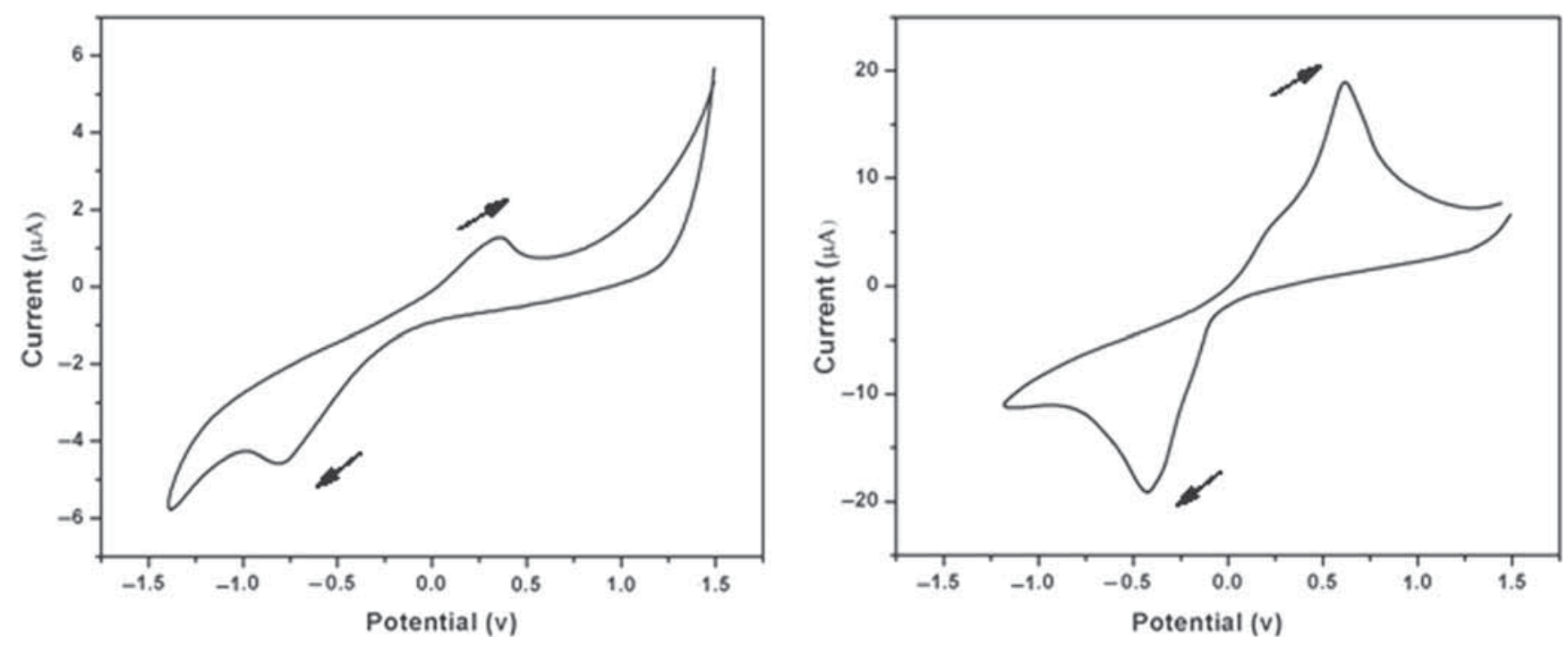

Figure 3. Cyclic voltammogram of $\mathrm{Cu}$ complex (Left) and (Right) $\mathrm{Cu}$ complex with 3,5-DTBC mixture in acetonitrile solution containing $0.1 \mathrm{M} \mathrm{TBAP}$ at $25^{\circ} \mathrm{C}$ using $\mathrm{Ag} / \mathrm{AgCl}$ reference electrode. Scan rate: $20 \mathrm{mV} \mathrm{s}^{-1}$. [Cu-complex] $=10^{-3} \mathrm{M}$, $[3,5-\mathrm{DTBC}]=0.1 \mathrm{M},[\mathrm{NaF}]=0.1 \mathrm{M}, \mathrm{T}=298.15 \mathrm{~K}$.

exhibiting $\mathrm{m}_{\mathrm{I}}$-dependent line widths, typically of copper (II) undergoing tumbling motion $\left(\mathbf{1}, \mathrm{A}_{\text {iso }}=57 \mathrm{G}\right)$. In order to detect the presence of organic radical, if any, produced as intermediate species and to understand the redox participation of the metal centers, we have recorded the X-band EPR spectra of the copper complex in acetonitrile solution of 3,5-DTBC. The shape of the $\mathrm{X}$-band EPR spectra of copper complex after addition of large excess of 3,5-DTBC (>1000 fold) to $10^{-4} \mathrm{M}$ solution of $\mathbf{1}$ in acetonitrile recorded at room temperature were similar to complexes in acetonitrile that is without addition of 3,5-DTBC (no change in $\mathrm{g}$ and A value for $\mathrm{Cu}^{2+}$ ) except for a weak signal due to 3,5-DTBC radical developed at $\mathrm{g}$ ca 2.0049. However, the intensity of EPR spectral lines for $\mathrm{Cu}^{+2}$ decreases with time and simultaneously a new single line (red coloured) appears with time. The reported $g$ value for oxidised DTB radical (semiquinone) is 2.0051 in $10^{-1} \mathrm{M} \mathrm{Bu}_{4} \mathrm{NPF}_{6} .{ }^{27}$ Thus, we assign the single line at $3450 \mathrm{G}$ to the semiquinone radical. It is important to note that the shape of the signal decreases uniformly which is assignable to the unselective reduction of copper(II). The reaction was also followed in the presence of a radical scavenger, TEMPO $($ TEMPO $=2,2,6$, 6-tetramethylpiperidinoxyl). Notably, no oxidation of catechol was observed in the presence of two equivalent of TEMPO with respect to the copper complex used. This result further confirms that catechol oxidation is catalyzed by the cationic $\mathrm{Cu}$ (II) units and indicated by radical generation (Scheme 2).

In the two proposed mechanisms, ${ }^{3 a, 7,8}$ the monodentate asymmetric coordination of the substrate has been proposed in Krebs's mechanism, ${ }^{7,8}$ whereas

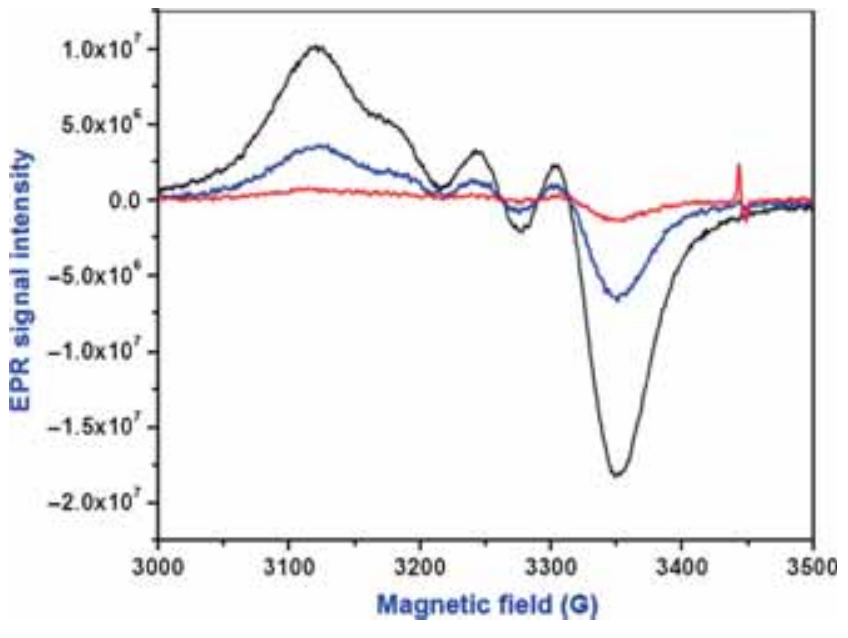

Figure 4. EPR spectra of $\mathrm{Cu}$ complex $1\left(10^{-4} \mathrm{M}\right)$ recorded at different time intervals after addition of 3,5-DTBC (excess) in acetonitrile. (a) black, $\mathrm{t}=0 \mathrm{sec}$; (b) blue, $\mathrm{t}=$ $2 \mathrm{~min}$; (c) red, $20 \mathrm{~min}$. All EPR spectra were recorded at room temperature. The single line appearing in EPR spectrum (red) at $3450 \mathrm{G}$ corresponds to the semiquinone radical.

simultaneous coordination of the substrate to both the copper centers (dinucleating bridging fashion) is suggested in the Solomon's mechanism. ${ }^{3 a}$ The ESI mass spectrum of the reaction mixture of a 1:100 ratio of copper complex and 3,5-DTBC in acetonitrile (Figure S6) exhibits the base peak at $\mathrm{m} / \mathrm{z}=243.10$ for 1 corresponding to the quinone sodium aggregate, [3,5-DTBQ$\mathrm{Na}]^{+}$. The peaks at $\mathrm{m} / \mathrm{z}=455.14$ and 486.9 corroborate the formation of $[\mathrm{Cu}(\mathrm{dpa})(\mathrm{DTBC})-\mathrm{H}]^{+}$and $[\mathrm{Cu}(\mathrm{dpa})$ (DTBC) $\left.\left(\mathrm{O}_{2}\right)-\mathrm{H}\right]^{+}$species respectively, as intermediates. To investigate the efficiency of the catalytic activity we draw a comparison between our $\mathrm{Cu}$ (II) complex 


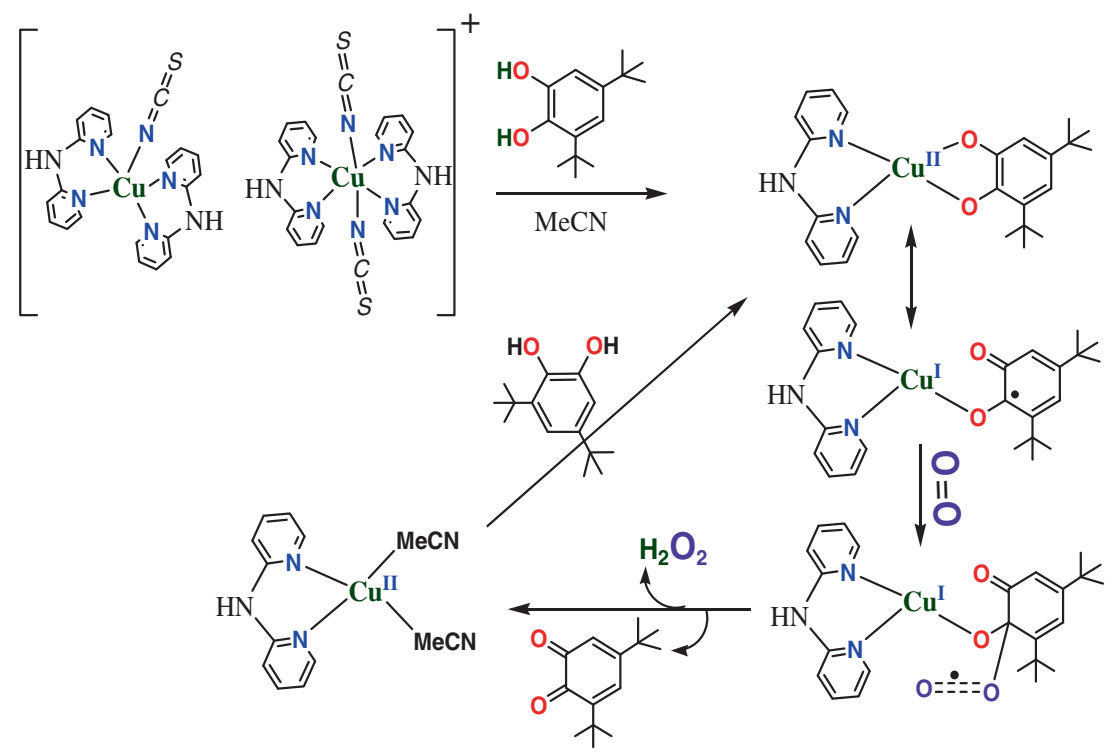

Scheme 2. Mechanistic aspects of catechol oxidation by $\mathrm{Cu}$ complex.

and a dinuclear copper complex with distant metal centers. $^{28}$ This comparison indicates that the heterogeometric copper(II) complex acts as a better and more effective catalyst towards catecholase activity than the reported one. ${ }^{28}$ Presence of multiple metal centers towards catecholase activity enhances the rate of catalytic oxidation in a significant manner since the availability of metal centers increases the possibility of formation of enzyme-substrate adduct which is fundamental for the catalytic oxidation by metal complexes.

\section{Conclusions}

In summary, though, similar types of structure are previously reported but herein, we report the novel addition of a new class of catalytic systems as discrete heterogeometric $\mathrm{Cu}$ (II) complexes containing dipyridylamine ligands and thiocyanate, $\left[\mathrm{Cu}(\mathrm{dpa})_{2} \mathrm{NCS}\right]_{2}\left[\mathrm{Cu}(\mathrm{dpa})_{2}\right.$ $\left.(\mathrm{NCS})_{2}\right]\left(\mathrm{ClO}_{4}\right)_{2}(\mathbf{1})$ which potentially mimics the full catalytic cycle of functional models of the active site of catechol oxidase enzyme with turnover number, $4.788 \times 10^{3} \mathrm{~h}^{-1}$ along with the production of benzoquinone and hydrogen peroxide. The generation of $\mathrm{Cu}(\mathrm{I})$ species in the catalytic pathways established by electrochemical analysis is further confirmed by electron paramagnetic resonance (EPR) spectroscopy. EPR analysis of the catechol in presence of $\mathrm{Cu}$ complexes indicates the generation of DTBC radical in solution and this radical plays the key role for promoting the aerobic oxidation of 3,5-DTBC to 3,5-DTBQ. Existence of isolated $\mathrm{Cu}^{\mathrm{II}}$ complex units in the course of catalysis significantly accounts for the reactivity of this complex.

\section{Supplementary information (SI)}

CCDC 1456703 contains the supplementary crystallographic data for $\mathbf{1}$. These data can be obtained free of charge via http://www.ccdc.cam.ac.uk/conts/retrieving. html, or from the Cambridge Crystallographic Data Centre, 12 Union Road, Cambridge CB2 1EZ, UK; fax: (+44) 1223-336-033; E. mail: deposit@ccdc.cam.ac.uk

All additional information pertaining to molecular packing diagram, H-bonding interaction, UV-Vis spectrum, EPR spectra at RT and LT, plot of substrate concentration vs. rate, and ESI mass spectrum of the reaction mixture are given in the supporting information available at www.ias.ac.in/chemsci.

\section{Acknowledgements}

The work is supported financially by the Science and Engineering Research Board (SERB), New Delhi, India under FAST TRACK SCHEME for YOUNG SCIENTIST (NO. SB/FT/CS-088/ 2013 dt. 21/05/2014). ARC thanks IISER Mohali for the X-ray facility available at the Department of Chemical Sciences. HRY thanks UGC, India for fellowship.

\section{References}

1. W Kaim and B Schwederski 1991 (Eds.) Bioanorganische Chemie (Stuttgart: Teubner)

2. Que L Jr 1993 In Bioinorganic Catalysis J Reedijk (Ed.) pp. 347-393 (New York: Marcel Dekker)

3. Simándi L I 1992 Advances in Catalytic Activation of Dioxygen by Metal Complexes (Dordrecht, Boston, London: Academic Publishers) 
4. (a) Solomon E I, Sundaram U M and Machonkin T E 1996 Chem. Rev. 96 2563; (b) G Parshall and S Ittel 1992 (Eds.) Homogeneous Catalysis $2^{\text {nd }}$ edition (New York: John Wiley); (c) Biswas B, Al-Hunaiti A, Räisänen MT, Ansalone S, Leskelä M, Repo T, Chen Y-T, Tsai H-L, Naik A D, Railliet A P, Garcia Y, Ghosh R and Kole N 2012 Eur. J. Inorg. Chem. 4479

5. Decker H, Dillinger R and Tuczek F 2000 Angew Chem. 1121656

6. Schindler S 2010 Eur. J. Inorg. Chem. 2311

7. Eicken C, Zippel F, Buldt-Karentzoloulos K and Krebs B 1998 FEBS Lett. 436293

8. Eicken C, Krebs B and Sacchettini J C 1999 Curr. Opin. Struct. Biol. 9677

9. Klabunde T, Eicken C, Sacchettini J C and Krebs B 1998 Nature Struct. Biol. 51084

10. Ackermann J, Meyer F, Kaifer E and Pritzkow H 2002 Chem. Eur. J. 8247

11. Kupán A, Kaizer J, Speier G, Giorgi M, Réglier M and Pollreisz F 2009 J. Inorg. Biochem. 103389

12. Majumder S, Sarkar S, Sasmal S, Sañudo E C and Mohanta S 2011 Inorg. Chem. 507540

13. Youngme S, Phuengphai P, Chaichit N, Mutikainen I, Turpeinen U and Murphy B M 2007 J. Coord. Chem. 60 131

14. Mesa J L, Urtiaga K, Lezama L and Arriortua M I 1999 Acta Chem. Scand. $\mathbf{5 3} 634$

15. Sletten J, Svardal K and Sørensen A 1993 Acta Chem. Scand. 471091

16. CrystalClear 2.0; Rigaku Corporation: Tokyo, Japan
17. Sheldrick G M 2008 Acta Cryst. A64 112

18. Dolomanov O V, Bourhis L J, Gildea R J, Howard J A K and Puschmann H 2009 J. Appl. Cryst. 42339

19. Nardelli M 1983 Comp. Chem. 795

20. Dey D, Kaur G, Ranjani A, Gyathri L, Chakraborty P, Adhikary J, Pasan J, Dhanasekaran D, Choudhury A R, Akbarsha M A, Kole N and Biswas B 2014 Eur. J. Inorg. Chem. 3350

21. Pal S, Chowdhury B, Patra M, Maji M and Biswas B 2015 Spectrochim. Acta Part A 144148

22. Basu P K, Mitra M, Ghosh A, Thander L, Lin C-H and Ghosh R 2014 J. Chem. Sci. 1261635

23. (a) Dey D, De A, Pal S, Mitra P, Ranjani A, Gayathri L, Chandraleka S, Dhanasekaran D, Akbarsha M A, Kole $\mathrm{N}$ and Biswas B 2015 Ind. J. Chem. A 54 170; (b) Kannappan R, Mahalakshmy R, Rajendiran T M, Venkatesan R and Rao P S 2003 J. Chem. Sci. 1151

24. Dey D, Das S, Yadav H R, Ranjani A, Gyathri L, Roy S, Guin P S, Dhanasekaran D, Choudhury A R, Akbarsh M A and Biswas B 2016 Polyhedron 106106

25. Tsuruya S, Yanai S-I and Masai M 1986 Inorg. Chem. 25141

26. Zippel F, Ahlers F, Werner R, Haase W, Nolting H-F and Krebs B 1996 Inorg. Chem. 353409

27. Hartl F 1995 Inorg. Chim. Acta 23299

28. Mendoza-Quijano M R, Ferrer-Sueta G, Flores-Álamo M, Aliaga-Alcalde N, Gómez-Vidales V, UgaldeSaldívara V M and Gasque L 2012 Dalton Trans. 41 4985 